extradimensional might still have been learned with more errors; the latter conclusion, however, would have to be tested. In any event, the intradimensional-extradimensional difference obtained in the present experiment would have been unaffected.

In conclusion, the main result of this experiment is consistent with the major prediction of a mediational interpretation of discrimination learning free from the potential biases Slamecka (1968) delineated (i.e., intradimensional shift was easier to learn than extradimensional shift). The discrepancy between the present results and Slamecka's (1969) result suggests that variables such as type of stimuli and number of dimensions used, in addition to $S$ and other task variables, may be important in concept shift experiments.

\section{REFERENCES}

DICKERSON, D. J. Performance of preschool children on three discrimination shifts. Psychonomic Science, 1966, 4, 417-418.

KELLEHER, R. T. Discrimination learning as function of reversal and nonreversal shift. Journal of Experimental Psychology, 1956, 51, 379-384.

KENDLER, H. H., \& KENDLER, T. S. Vertical and horizontal processes in problem solving. Psychological Review, $1962,69,1-16$.

KENDLER, T. S., KENDLER, H. H., \& WELLS, D. Reversal and nonreversal shifts in kindergarten children. Journal of Experimental Psychology, 1959, 58, $56-60$.

LeBOW, M. D. Transfer learning in chronic schizophrenics. Journal of Consulting \& Clinical Psychology, 1970a, in press.

LeBOW, M. D. Age, degree of training, and type of extradimensional shift in normally intelligent humans. Journal of Experimental Education, 1970b, in press.

SLAMECKA, N. J. A methodological analysis of shift paradigms in human discrimination learning. Psychological Bulletin, 1968, 69 . 423-438.

SLAMECKA, N. J. An improved discrimination-shift design. Psychonomic Science, 1969, 17, 89.

WOLFF, J. L. Concept-shift and discrimination-reversal learning in humans. Psychological Bulletin, 1967, 68, 369-408.

\title{
Relational mnemonics in category clustering: The correlates of word frequency,
} familiarity, and category-name variables

\author{
JOHN H. BOWEN \\ State University of New York at Albany, Albany, N.Y. 12203
}

The reported use of relational or rote recall techniques in a category-clustering paradigm was examined as a function of (1) the frequencies of occurrence of the nouns being recalled, (2) the familiarity scale values of the nouns, and (3) the availability of instructions containing category-name cues. Results indicate that: (1) with relational techniques being used in higher proportions than rote techniques, the difference between types of techniques was an increasing function of frequency of occurrence; (2) for low-familiarity words, the use of relational techniques increased more rapidly with increasing frequency of occurrence for instructed groups than for uninstructed groups; and (3) increasing word frequency was associated with decreasing differences between familiarity conditions for both types of techniques. An explanation, based upon assumptions concerning associative relationships, is offered for the results.

There has been a growing interest in the mnemonic rules, codes, or strategies which Ss use in organized recall (e.g., Pollio \& Gerow, 1968). Evidence suggests that the reported use of associative or relational strategies is related to better free recall than is the reported use of rote strategies (Eagle, 1967). Therefore, it would seem valuable to determine if, in organized recall, the reported use of relational and rote strategies is related to the manipulation of variables commonly used in the study of learning and coding.

The Ss were asked to report the strategies used in a category-clustering investigation which manipulated the frequency of occurrence and familiarity scale values of the words and the availability of category names (Bowen, 1970). The proportions of relational and rote strategies are reported here as functions of those variables.

The treatment variables were: (1) three T-L frequencies of occurrence of the stimulus words-. $22<1$ words per million (wpm), 1-4 wpm, and 5-100+wpm

*The writer gratefully acknowledges the support of a research grant and faculty research fellowship from the Research Foundation of the State University of New York. Also acknowledged with gratitude is the assistance of Carlton Aldrich.
(Thorndike \& Lorge, 1944); (2) two levels of familiarity scale values-low (L) and high (H) familiarity; and (3) two levels of category-name instructions-instructions (I) and no instructions (NI). A complete description of the familiarity scaling and frequency characteristics of the words is to be found elsewhere (Bowen, 1969a)

Words in each combination of frequency of occurrence and familiarity level were equally subdivided into four conceptual categories: names of occupations, animals, articles of dress, and persons. The I groups were told the names of the categories immediately prior to stimulus presentation and again immediately prior to recall. The NI groups were not told category names.

The words were presented once to the Ss in each experimental group, and, following presentation and an opportunity for writing recalls, the Ss were asked to describe the techniques which they had used in attempting to remember the words.

Techniques were classified by first reading all responses and taking notes with key phrases from the responses. Second, general descriptions were developed for the response categories. Responses then were classified independently by two judges, the $\mathrm{E}$ and his assistant, without reference to each S's treatment combination or 


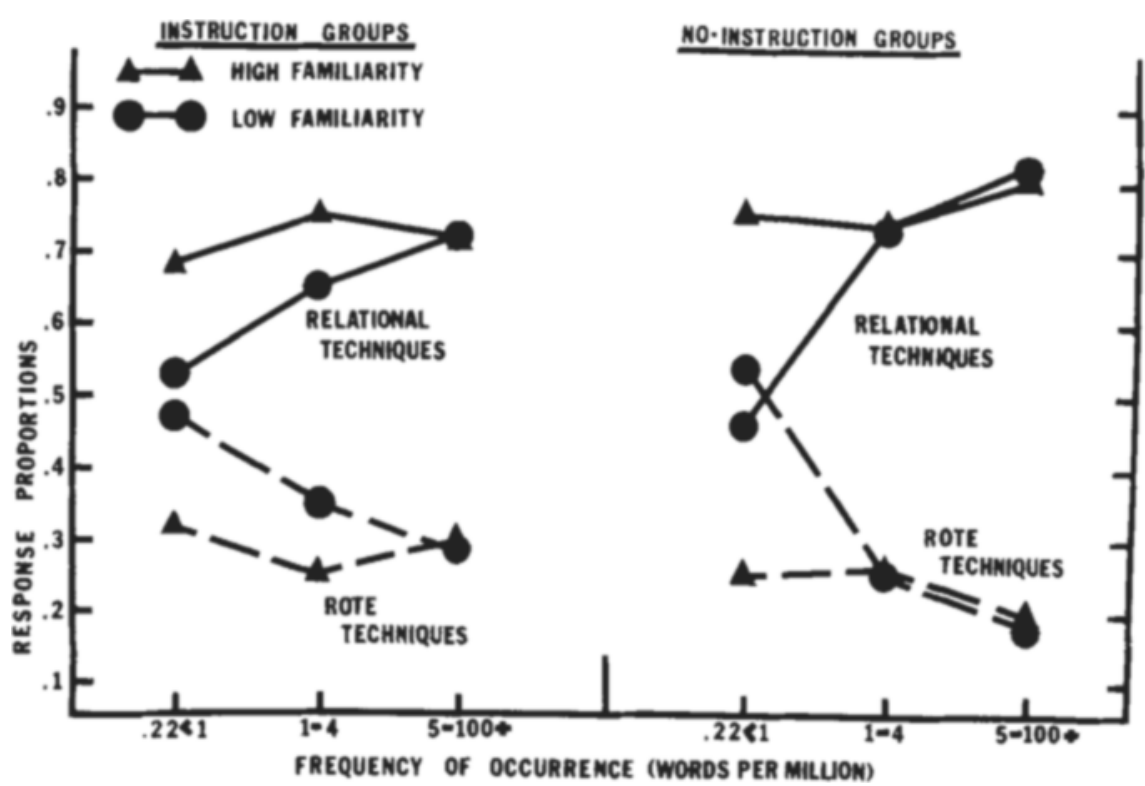

clustering score. The responses in categories which suggested the use of relationality were combined and classified as relational, while responses in the remaining categories were classified as rote. The categorization of fewer than $1 \%$ of the responses led to disagreement between the judges. These responses were not included in the results. Examples of responses which were classified as relational were: "I tried to remember the words by relating them to the names of people I know"; "I tried to relate the words in a sentence"; "I tried to relate the words through the letters of the alphabet." Examples of responses which were classified as rote were: "I tried to remember the first (or last) words given"; "I just tried to remember the words in the order in which they were given."

\section{RESULTS AND DISCUSSION}

Figure 1 presents the proportions of relational and rote responses for all treatment groups. Statistical tests used a critical region of $p=.05$. The first comparisons determine whether proportions of reported relational and rote techniques were related to frequencies of occurrence within the instruction (I) and no instruction (NI) conditions, while the familiarity variable was ignored. Within both groups the use of relational or rote techniques was dependent upon the frequencies of the words being recalled I I, $x^{2}(2 \mathrm{df})=6.75 ; \mathrm{NI}$, $\left.x^{2}(2 \mathrm{df})=7.01\right]$. Figure 1 shows both results to indicate interaction effects because of an increasing difference between relational and rote techniques as a function of increasing word frequency. Relational techniques were consistently used in higher proportions than rote techniques.

The next comparisons deal with the question of whether or not the use of relational or rote techniques was dependent upon availability of category names and word frequency within familiarity conditions. For high-familiarity words, there was no relationship between the instructional variable and frequency of occurrence in the use of either relational $\left[\mathrm{x}^{2}(2 \mathrm{df})=1.68\right]$ or rote $\left[x^{2}(2 \mathrm{~d} f)=3.53\right]$ techniques. However, for low familiarity words, the effects of instructions interacted with frequency of occurrence in the reported use of relational $\left[\mathrm{x}^{2}(2 \mathrm{df})=24.68\right]$ and rote $\left[x^{2}(2 \mathrm{df})=19.29\right]$ techniques. For low-familiarity words, the use of relational techniques increases more rapidly with increasing frequency of occurrence for NI groups than for I groups. Reported use of rote techniques shows the converse of this relationship.

Finally, comparisons were made to determine whether reported use of relational or rote techniques was dependent upon word frequency and familiarity within each instructional group. Familiarity interacted with frequency $\left[x^{2}(2 \mathrm{df})=45.98\right]$ in the reported use of relational techniques within the I groups, while for the NI groups there was no relationship between familiarity and frequency effects $\left[x^{2}(2 \mathrm{df})=.69\right]$. In the reported use of rote techniques, familiarity and frequency interacted for $I\left[x^{2}(2 \mathrm{df})=6.25\right]$ and for NI $\left[x^{2}(2 \mathrm{df})=7.35\right]$. The significant interactions show that increasing frequency of vccurrence is associated with decreasing differences between familiarity conditions in the use of either relational or rote techniques.

There is ample evidence that associative relationships among words are a basis for organized recall (Cofer, 1965). The results presented here can satisfactorily be explained in the context of associative relationships. Assume, first, that associative relationships increase as functions of increasing word familiarity (Ward, 1967), increasing frequency of occurrence of the words (Deese, 1965), and the availability of category name cues (Goss, 1963). Assume, also, that the attempted use of relational techniques directly reflects the strength of associative relationships, while the attempted use of rote techniques is inversely related to the strength of such relationships. Given the assumptions, it can be inferred from the results that associative relations were maximal for high-familiarity words and that little was contributed to associative relations or the use of relational techniques by increasing frequency of occurrence or by making available category name cues. By contrast, the interactions support the inferences that: (1) associative relationships increase with increasing frequency for low-familiarity words and (2) the availability of category name cues increases such relationships more for low-frequency than for high-frequency words.

\section{REFERENCES}

BOWEN, J. H. Familiarity scale values for 420 nouns in twelve combinations of frequency of occurrence and conceptual categorization. Psychological Reports. 1969a. 25. (Monograph Supplement 3).

BOWEN, J $H$. The effects on category clustering of category-name cues and the frequencies of occurrence and familiarity scale values of nouns. Psychological Reports, 1970, 27, 859-864.

COFER. C. N, Some factors in the organizational characteristics of free recall. American Psychologist. 1965, 20, 261-272.

DEESE, J. Frequency of usage and number of words in free recall: The role of associations. Psychological Reports, $1960,7,337-344$.

EAGLE. M. N. The effect of learning strategies upon free recall. American Journal of Psychology, 1967, 80 $421-425$.

GOSS, A. Comments on Professor Noble's paper. In C. N. Cofer and B. S. Musgrave (Eds.). Verbal behavior and learning. New York: McGraw-Hill, 1963.

POLLIO, H. R., \& GEROW, J, R. The role of rules in recall. American Journal of Psychology, 1968, 81, 303-313.

THORNDIKE, E, L., \& LORGE, I. The teacher's word book of 30,000 words. New York: Bureau of Publications, Teacher's College, Columbia University, 1944

WARD, V. P. Clustering as a function of frequency of occurrence, familiarity and meaningfulness of stimuli. Unpublished MS thesis, State University of New York, Albany. 1967. 